\title{
Update on fertility preservation for younger women with breast cancer
}

\author{
Ellen Warner MD MSc, Karen Glass MD, Shu Foong MD, Emily Sandwith MD
}

Cite as: CMAJ 2020 August 31;192:E1003-9. doi: 10.1503/cmaj.200245

CMAJ Podcasts: author interview at www.cmaj.ca/lookup/doi/10.1503/cmaj.200245/tab-related-content

B reast cancer is the most common cancer in Canadian women, including those of reproductive age. ${ }^{1}$ About $50 \%$ of women aged 40 years or younger in developed countries currently diagnosed with breast cancer have not yet completed their families, possibly because of delayed childbearing. ${ }^{2,3}$ Although $80 \%$ of patients in this age group without distant metastatic disease at presentation are expected to be long-term survivors (disease-free for $\geq 20 \mathrm{yr}$ and likely cured ${ }^{1}$ ), largely owing to advances in adjuvant chemotherapy and hormonal therapy, most of these life-saving treatments adversely affect fertility. Potential loss of fertility has been shown to affect treatment decisions. ${ }^{4}$ Among the concerns of younger breast cancer survivors, fertility issues rank second only to fear of cancer recurrence. ${ }^{5,6}$ Egg donation, surrogacy and adoption are potential options for women rendered infertile by their treatment; however, even if these options were simple, inexpensive and widely available - which they are not - many women may prefer to be the biologic mother of their children. Effective and safe fertility-preservation options are available and are now government-funded for many women in Ontario and Quebec, Canada. In a survey of European patients with breast cancer who received fertility-preservation counselling, most reported that it instilled a profound feeling of hope and was instrumental in improving their coping, regardless of whether they ultimately chose to pursue fertility preservation. ${ }^{3}$

Nevertheless, a recent study aimed at increasing attention to fertility issues at oncology centres showed that about $50 \%$ of women who were planning to have children before their breast cancer diagnosis were not referred for fertility-preservation counselling. ${ }^{7}$ Many patients who do not access fertility preservation ultimately experience deep regret. ${ }^{4}$ The prevalence among health care providers of unfounded concerns about the safety and effectiveness of these procedures, which may lead to patients' being discouraged from accessing fertility preservation, is also disconcerting. ${ }^{8}$

We provide a brief summary of the impact of breast cancer treatment on ovarian function, review the most common fertility-preservation options available for young patients with breast cancer, and summarize the evidence supporting the safety of ovarian stimulation and post-treatment pregnancy for

\section{KEY POINTS}

- For the many women with breast cancer who have not completed their families at the time of their cancer diagnosis, treatment-related infertility may become a major source of distress, which can usually be prevented if fertility preservation is performed before systemic treatment is started.

- Ovarian stimulation for oocyte or embryo cryopreservation can now be started at any point in the menstrual cycle and completed within 2 weeks.

- Women without a male partner at the time of oocyte retrieval can freeze their oocytes and be reassured that the probability of a successful future pregnancy (after oocyte thawing and in vitro fertilization) is similar to that achieved after implantation of previously cryopreserved embryos.

- For women who decline or are unable to undergo cryopreservation, ovarian function suppression with a gonadotropin-releasing hormone agonist during chemotherapy reduces the gonadotoxicity of chemotherapy and may increase the odds of natural conception in the future.

- No study to date has shown an increased risk of breast cancer recurrence in women who become pregnant after completing breast cancer treatment regardless of the time since the cancer diagnosis; similarly, no study has shown any adverse cancerrelated effects from ovarian stimulation before treatment or from ovarian function suppression during chemotherapy.

this population (Box 1). We also provide a list of relevant resources for patients and health care providers. Although the focus is on patients with breast cancer, some information will apply to any patient about to receive gonadotoxic therapy for treatment of a cancer not involving the ovaries.

\section{How does breast cancer treatment affect ovarian function?}

Women are born with a finite number of oocytes, also known as ovarian reserve. This pool of oocytes declines over time until menopause or ovarian failure. As ovarian reserve declines, so does fertility. ${ }^{9}$ 


\section{Box 1: Evidence used in this review}

We conducted a MEDLINE search of all English-language articles published between Jan. 1, 2017, and Nov. 27, 2019, using the following search terms: "exp Breast Neoplasms" and 1) ("exp Fertility Preservation)" or 2) ("fertility or oocyte or egg or embryo or ovarian tissue") ("preservation" or "cryopreservation" or "freezing" textwords) or 3) ("pregnancy" or "pregnant" or "fertility") (after or post) ("breast cancer" or "breast neoplasm" or "breast carcinoma") or 4) "prevention" or "chemotherapy" and "gonadotoxicity") or 5) "controlled ovarian stimulation" or "controlled ovarian hyperstimulation" or 6) "ovarian suppression" or "ovarian function suppression" and "fertility." A total of 195 abstracts were retrieved, of which 56 studies, reviews or meta-analyses were considered relevant to the clinical questions addressed in the current review. We also reviewed selected references cited in the 56 papers.

As breast cancer in patients aged 40 or younger is generally diagnosed at a later stage and is more biologically aggressive than breast cancer detected in older women, most patients in this age group will require chemotherapy. ${ }^{10}$ The harmful effects of chemotherapeutic agents on the ovary are variable and depend on the specific agent used, the cumulative treatment dosage, the patient's age and her underlying ovarian reserve. ${ }^{11}$ Chemotherapy usually causes at least a temporary period of amenorrhea owing to damage to developing preovulatory ovarian follicles. ${ }^{12}$ Resumption of menses generally occurs within 3-4 months but may take up to 2 years. However, if ovarian reserve has been depleted to the point of ovarian failure, menstruation does not resume. Cyclophosphamide, an alkylating agent used in most adjuvant chemotherapy regimens, is particularly toxic to the ovary, and the detrimental effects are greater in older women. ${ }^{13}$ With today's most commonly used breast cancer chemotherapy regimens (which generally include cyclophosphamide, together with adriamycin or epirubicin, with or without a taxane), women treated before age 41 have a $9 \%-46 \%$ risk of permanent ovarian failure; among those aged 41 or older, the risk is substantially higher. ${ }^{13,14}$ The taxanes - paclitaxel and docetaxel - appear to have only a small effect on ovarian function, whereas the anti-human epidermal growth factor receptor 2 monoclonal antibody trastuzumab is not gonadotoxic. ${ }^{13}$ Women with early-stage breast cancer overexpressing human epidermal growth factor receptor 2 who are treated with singleagent paclitaxel and trastuzumab therefore have a lower risk of ovarian failure.

It is difficult to assess the detrimental effects of chemotherapeutic drugs on fertility in women who begin menstruating again after treatment. Changes in serum anti-Müllerian hormone level and antral follicle count (measured by transvaginal ultrasonography) correlate with loss of ovarian reserve but are not necessarily predictive of future fertility. ${ }^{15}$ Since regular ovulatory cycles can be maintained by only $10 \%$ of the ovary, return of menses does not rule out loss of fertility. ${ }^{16}$ In addition, even if not rendered immediately infertile, most women treated with an alkylating agent will experience loss of fertility and menopause at an earlier age than they would have otherwise, ${ }^{17}$ with estimates suggesting that chemotherapy treatments will "age" the ovaries by $5-10$ years in terms of reproductive function. ${ }^{18}$

About two-thirds of young patients with breast cancer have estrogen-receptor-positive $(\mathrm{ER}+)$ disease ${ }^{19}$ and all but those with noninvasive or minimally invasive disease require 5-10 years of adjuvant anti-estrogen therapy because of the hormone responsiveness of the tumour. Although endocrine therapy does not affect ovarian function directly, it is likely to result in childbearing delay and consequently natural agerelated decline in fertility. Patients with endocrine-unresponsive (ER-) disease often wait 2-3 years after diagnosis, when the risk of distant recurrence is highest, before attempting pregnancy. This is because distant recurrence is almost invariably incurable, and most women would not want to bear a child likely to lose his or her mother before reaching adulthood. Since radiation to the breast, chest wall or regional lymphatics does not encompass the pelvis, there is no impact of radiation on ovarian function.

The American Society of Clinical Oncology strongly recommended in 2006, ${ }^{20} 2013^{21}$ and $2018^{22}$ that the option of fertility preservation be discussed as soon as possible after a cancer diagnosis with any patient of reproductive age whose fertility might be affected by his or her cancer treatment. This recommendation would apply to the majority of newly diagnosed young patients with breast cancer without distant metastases.

\section{What fertility preservation options are available?}

The most commonly used ovarian preservation options for patients with breast cancer are outlined in Table 1.

\section{Embryo and oocyte cryopreservation}

Embryo cryopreservation has been available for many years. It requires sperm from a male partner or donor, and involves oocyte retrieval, in vitro fertilization and cryopreservation of the resulting embryos for future use. Pregnancy and live birth rates are dependent on the woman's age at the time of oocyte retrieval and the number of embryos cryopreserved (Figure 1). ${ }^{20,23}$

Cryopreservation of the unfertilized oocyte has been much more successful since the development of vitrification, an ultraquick cooling process that prevents crystal formation. ${ }^{24}$ When pregnancy is desired, oocytes are thawed and fertilized in vitro, and the resultant embryos are transferred into the woman's uterus. ${ }^{25}$ Oocyte cryopreservation is a good option for women who do not have a male partner, who desire reproductive autonomy, or who have religious or ethical objections to embryo freezing. ${ }^{22}$ Pregnancy and live birth rates are still dependent on the number of oocytes retrieved and the woman's age at the time of retrieval but now approach those obtained with embryo cryopreservation for women aged younger than 35 years at the time of retrieval (Figure 1). ${ }^{24,26,27}$

Embryo and oocyte cryopreservation require similar controlled ovarian-stimulation cycles. The exact protocol used is dependent on the patient's age and ovarian reserve but typically entails 10-12 days of daily gonadotropin injections to stimulate 
the ovaries to produce multiple follicles. The follicles are monitored closely during this period with transvaginal ultrasonography and serum hormone testing. This process is generally well tolerated, and most women can maintain their daily routines.
Once the follicles reach an appropriate size, a trigger shot is given to mature the oocytes. Oocyte retrieval is then performed 34-36 hours later by means of an ultrasonography-guided transvaginal procedure under conscious sedation. Thus, the entire

Table 1: Most commonly used ovarian preservation options for patients with breast cancer

Option

\begin{tabular}{|c|c|c|c|c|}
\hline Characteristic & Ovarian suppression & Embryo freezing & Egg freezing & Ovarian tissue freezing \\
\hline Definition & $\begin{array}{l}\text { Monthly injection of a } \\
\text { gonadotropin-releasing } \\
\text { hormone agonist to } \\
\text { suppress ovulation and } \\
\text { menstruation }\end{array}$ & $\begin{array}{l}\text { IVF and freezing of embryos for } \\
\text { later transfer }\end{array}$ & $\begin{array}{l}\text { Hormonal stimulation, } \\
\text { harvesting and freezing of } \\
\text { oocytes for later fertilization } \\
\text { and transfer }\end{array}$ & $\begin{array}{l}\text { Removal and freezing of } \\
\text { ovarian tissue and } \\
\text { reimplantation of tissue } \\
\text { after chemotherapy }\end{array}$ \\
\hline Timing & $\begin{array}{l}\text { Ideally, start at least } 1 \mathrm{wk} \\
\text { before first chemotherapy } \\
\text { treatment and continue } \\
\text { until chemotherapy is } \\
\text { completed ( } 3-6 \mathrm{mo})\end{array}$ & $\begin{array}{l}\text { Before first chemotherapy } \\
\text { treatment (or hormone treatment } \\
\text { if no chemotherapy given) }\end{array}$ & $\begin{array}{l}\text { Before first chemotherapy } \\
\text { treatment (or hormone } \\
\text { treatment if no } \\
\text { chemotherapy given) }\end{array}$ & $\begin{array}{l}\text { Ideally before first } \\
\text { chemotherapy treatment } \\
\text { (or hormone treatment if } \\
\text { no chemotherapy given) }\end{array}$ \\
\hline $\begin{array}{l}\text { Average delay } \\
\text { for start of } \\
\text { chemotherapy }\end{array}$ & $\begin{array}{l}\sim 7-10 \text { d until suppression } \\
\text { reached }\end{array}$ & $\sim 2 \mathrm{wk}$ & $\sim 2 \mathrm{wk}$ & $\begin{array}{l}\text { - Operating room time } \\
\text { needed to perform } \\
\text { laparoscopy and } \\
\text { remove part of or an } \\
\text { entire ovary } \\
\text { - No delay to 2-wk wait }\end{array}$ \\
\hline Success rate & $\begin{array}{l}\text { - } 15 \% \text { of eggs protected } \\
\text { Degree of fertility } \\
\text { protection is unknown; } \\
\text { however, the timing of } \\
\text { premature ovarian } \\
\text { failure is generally } \\
\text { delayed }\end{array}$ & $\begin{array}{l}\text { Age-dependent; } 30 \%-50 \% \text { per } \\
\text { embryo transfer (see Figure 1) }\end{array}$ & $\begin{array}{l}\text { Age-dependent: for women } \\
<36 \mathrm{yr} \text {, live birth rate is } 20 \% \\
\text { lower than for equal } \\
\text { number of frozen embryos; } \\
\text { difference increases with } \\
\text { increasing age (see Figure 1) }\end{array}$ & $\begin{array}{l}\text { - Previously considered } \\
\text { experimental in } \\
\text { Canada; status } \\
\text { changing currently } \\
\text { - Widely performed } \\
\text { outside North America } \\
\text { in women aged } \leq 35 \mathrm{yr} \\
\text { - Graft longevity is limited } \\
\text { - Limited information on } \\
\text { success rate but } \\
\text { promising }\end{array}$ \\
\hline $\begin{array}{l}\text { Average cost and } \\
\text { locations }\end{array}$ & $\begin{array}{l}\text { \$425 per month; } \\
\text { usually covered by } \\
\text { private health plans and } \\
\text { government funding } \\
\text { - Widely available across } \\
\text { Canada at all cancer } \\
\text { treatment centres and } \\
\text { fertility clinics }\end{array}$ & $\begin{array}{l}\text { - } \$ 3600-\$ 7000, \text { plus medications } \\
(\$ 2000-\$ 5000) \\
\text { - Processing of donor sperm } \\
\sim \$ 1000^{*} \\
\text { - Annual storage fee } \$ 300-\$ 500 \\
\text { - May be covered; dependent on } \\
\text { clinic and province } \\
\text { - Compassionate medication often } \\
\text { available } \\
\text { - Funding may be available locally } \\
\text { or through Fertile Future } \dagger \\
\text { - Available at all IVF clinics in } \\
\text { Canada }\end{array}$ & $\begin{array}{l}\text { - } \$ 3600-\$ 7000, \text { plus } \\
\text { medications }(\$ 2000-\$ 5000) \\
\text { - Annual storage fee } \\
\$ 300-\$ 500 \\
\text { - May be covered; } \\
\text { dependent on clinic and } \\
\text { province } \\
\text { - Compassionate } \\
\text { medication often available } \\
\text { - Funding may be available } \\
\text { locally or through Fertile } \\
\text { Future† } \\
\text { - Available at all IVF clinics } \\
\text { in Canada }\end{array}$ & $\begin{array}{l}\text { - } ~ \$ 1500 \\
\text { - Laparoscopy is covered } \\
\text { by most provincial } \\
\text { health plans } \\
\text { - Cost of freezing tissue is } \\
\text { clinic dependent; } \\
\text { covered only in Quebec } \\
\text { - Few clinics in Canada } \\
\text { do this }\end{array}$ \\
\hline $\begin{array}{l}\text { Special } \\
\text { considerations }\end{array}$ & $\begin{array}{l}\text { - May be combined with } \\
\text { any of the other options } \\
\text { - First injection should be } \\
\text { administered in early } \\
\text { follicular phase or mid } \\
\text { luteal phase }\end{array}$ & $\begin{array}{l}\text { - Need partner or donor sperm } \\
\text { - May test embryos genetically for } \\
B R C A \text { or other deleterious } \\
\text { mutation if patient is a carrier and } \\
\text { then select only unaffected } \\
\text { embryos for transfer } \\
\text { - Preimplantation genetic testing } \\
\text { cost }(\$ 8000-\$ 10000) \text { not included } \\
\text { in provinces with fertility } \\
\text { preservation funding }\end{array}$ & $\begin{array}{l}\text { Most popular option for } \\
\text { single women or those } \\
\text { opposed to embryo creation } \\
\text { or freezing or both }\end{array}$ & $\begin{array}{l}\text { Tissue is not suitable for } \\
\text { transplantation if there is } \\
\text { a high risk of ovarian } \\
\text { metastases or cancer }\end{array}$ \\
\hline
\end{tabular}




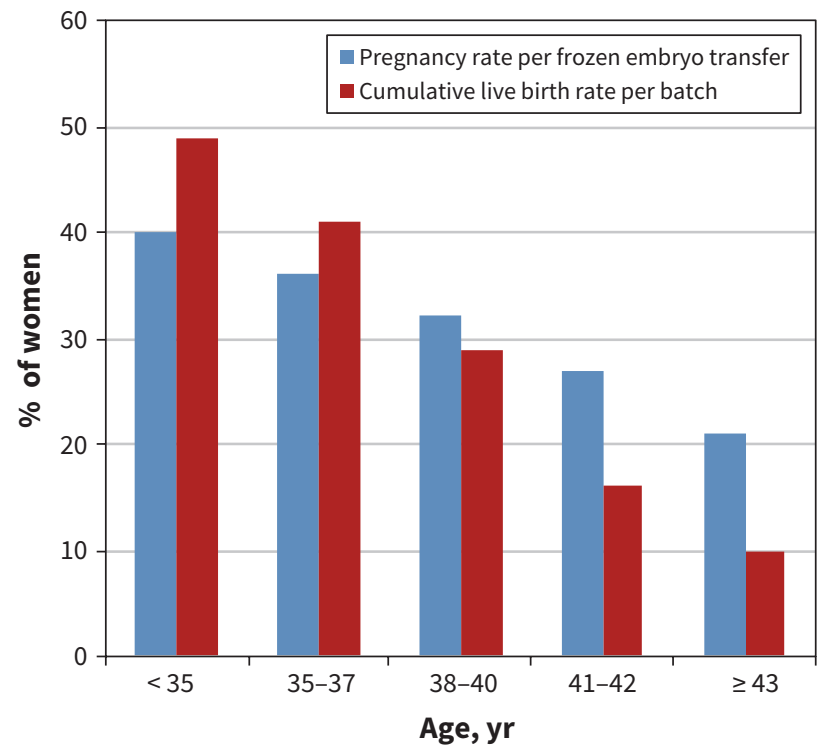

Figure 1: Success rates for embryo cryopreservation per batch of harvested oocytes from 1 cycle of ovarian stimulation, by patient age.

process takes $12-14$ days. ${ }^{28}$ Although cryopreserved embryos and oocytes are believed to be preserved indefinitely, each fertility clinic in Canada has defined an upper age limit for undergoing embryo transfer.

Ovarian-stimulation protocols in the past were timed with the follicular phase of a woman's menstrual cycle, sometimes necessitating a delay of almost 1 month before fertilitypreservation treatments could be initiated. Increasing evidence supports random-start protocols whereby ovarian stimulation can be initiated at any time in the menstrual cycle, which minimizes any treatment delay. ${ }^{28}$ This also enables a second ovarian-stimulation cycle to be initiated almost immediately if the number of eggs retrieved with the first cycle is inadequate, a situation commonly observed with BRCA mutation carriers. ${ }^{29}$ Thus, for women who will be treated first with surgery, referral to a fertility clinic before surgery offers them more options. Most important, current protocols prevent treatment delay for the increasing number of women who are receiving (neoadjuvant) chemotherapy before removal of the primary tumour, as egg harvesting can be completed during the time it generally takes for tumour staging, central line insertion and measurement of the cardiac ejection fraction (2-3 wk).

About $10 \%-15 \%$ of women aged 40 or younger diagnosed with breast cancer have autosomal dominant BRCA1 or BRCA2 germline mutations, which confer about a $70 \%$ lifetime risk of breast cancer and a 15\%-45\% risk of fallopian tube or ovarian cancer in women (as well as a lesser increased risk of certain cancers in men). Oocyte or embryo cryopreservation (before chemotherapy or in the absence of a breast cancer diagnosis) enables these women to undergo prophylactic salpingooophorectomy to reduce their future risk of tubo-ovarian or (a second) breast cancer, even if they have not yet completed their families. As an added benefit, patients who wish to avoid the $50 \%$ chance of transmitting the mutation to their offspring can elect to undergo preimplantation genetic testing at the time of in vitro fertilization and transfer only unaffected embryos. ${ }^{29}$

One of the limitations of embryo and oocyte cryopreservation may be the cost associated with these procedures (Table 1). At present, Ontario funds 1 cycle of cryopreservation before cancer treatment or, for BRCA mutation carriers, before prophylactic salpingo-oophorectomy. Quebec funds 1 or more cycles of cryopreservation before cancer treatment only. Given the importance of fertility-preservation procedures, we hope that other provinces will soon join in funding the procedure for patients with cancer, as cost should not prevent access to such treatment.

\section{Ovarian tissue cryopreservation}

Although ovarian tissue cryopreservation and subsequent transplantation is still in the early stages of adoption and implementation in Canada, reported results are promising, ${ }^{30}$ and the procedure has recently been reclassified as nonexperimental by the American Society of Reproductive Medicine. ${ }^{31}$ Ovarian tissue cryopreservation involves surgical removal of unstimulated ovarian tissue that is then cryopreserved. The tissue is subsequently thawed and transplanted back into the patient after completion of cancer therapy. This ovarian tissue usually becomes hormonally active about 4-5 months after transplantation. ${ }^{30}$ There has been concern that cancer cells may reside in the ovary and may be reintroduced, ${ }^{28}$ but molecular testing for such cells is generally done, and, to date, there have been no reported cases of this potential complication. Although ovarian tissue cryopreservation theoretically can be performed more quickly than ovarian stimulation, in Canada, the logistics of finding operating room time and availability of programs to process the ovarian tissue are challenging. Furthermore, the cost of the laparoscopy procedure is not covered in all provinces, and the cost of tissue freezing is covered only in Quebec (Table 1).

\section{Ovarian suppression with gonadotropin-releasing hormone agonists}

Injection of a gonadotropin-releasing hormone agonist such as leuprolide ( $3.75 \mathrm{mg}$ injected intramuscularly into the buttock) or goserelin (3.6-mg pellet injected subcutaneously into the abdomen) at least 1 week before chemotherapy and then every 4 weeks until the end of chemotherapy has been shown in randomized studies and subsequent meta-analyses to reduce the risk of permanent amenorrhea. ${ }^{32}$ In the largest meta-analysis to date, published in 2015, the premature ovarian failure rate among 1231 patients with breast cancer was reduced from $34 \%$ to $19 \%$ (odds ratio [OR] $0.36,95 \%$ confidence interval [CI] $0.23-$ $0.57) .{ }^{33}$ A 2018 meta-analysis of the 5 largest breast cancer studies using individual patient-level data showed similar results. ${ }^{34}$ Chemotherapy regimens used in these studies were similar to or more gonadotoxic than those in current use. Several different mechanisms of action have been postulated, including decreased ovarian perfusion leading to reduced delivery of chemotherapy, prevention of recruitment of primordial follicles and upregulation of anti-apoptotic pathways. ${ }^{28}$ 
The first injection should be administered at least a week before the start of chemotherapy to avoid the initial phase of gonadotropin surge before receptor downregulation occurs. A major limitation of the existing literature is that most studies used amenorrhea as the primary outcome, with relatively few pregnancy attempts documented during the study period. Although the 2015 meta-analysis showed a statistically significant increase in the number of pregnancies in woman treated versus not treated with a gonadotropin-releasing hormone agonist (37 [10.5\%] v. 20 [5.5\%], $p=0.03),{ }^{33}$ pregnancy intent in the 2 groups was not evaluated. In its most recent update, the American Society of Clinical Oncology advises women who wish to maximize their post-treatment fertility to not view this option as an alternative to egg or embryo cryopreservation. ${ }^{22}$

\section{Are fertility preservation and pregnancy after breast cancer safe?}

Because most breast cancers are $\mathrm{ER+}$, even among younger women, exposing these women to high physiologic or pharmacologic levels of female hormones is understandably concerning. Answering research questions about the safety of pregnancy after breast cancer is particularly complicated since randomized controlled trials are not possible. Limited evidence exists to guide practice.

\section{Pregnancy achieved through natural conception}

Until relatively recently, no definitive data existed regarding the safety of pregnancy after breast cancer, and many women who became pregnant, particularly if they had ER+ disease, were advised to abort because of the very high estrogen levels associated with pregnancy. In a 2018 observational study, Lambertini and colleagues ${ }^{35}$ matched 333 patients with pregnancy after breast cancer to 874 nonpregnant patients with breast cancer and followed the participants for a median of 9.6 years after diagnosis and 7.2 years after pregnancy. For the $57 \%$ of women with ER+ disease, there was no difference in disease-free survival (hazard ratio [HR] $0.94,95 \% \mathrm{Cl} 0.70-1.26$ ) or overall survival (HR 0.84, 95\% Cl 0.60-1.18). Interestingly, for ER- patients, better overall survival was seen in the pregnant cohort (HR 0.57, $95 \% \mathrm{Cl} 0.36-0.90)$. In addition, no difference in disease-free survival was seen in the subgroup of women who breastfed compared to those who did not. A recent observational study in an Asian population showed significantly lower mortality among the patients who became pregnant than among those who did not, particularly in the ER+ subgroup. ${ }^{36}$

There is no agreement on the best time to conceive after breast cancer diagnosis. Most ER- tumours that recur do so in the first 2-3 years after treatment; therefore, many women choose to wait until after that period to attempt pregnancy. For women with ER+ tumours, the situation is more complex, as they are encouraged to complete 5-10 years of adjuvant hormonal therapy, during which time pregnancy is contraindicated (as tamoxifen is teratogenic ${ }^{37}$ ) or physiologically impossible (with ovarian function suppression and an aromatase inhibitor). However, there is no evidence to date from retrospective studies that interrupting hormonal treatment early to become pregnant increases the risk of recurrence. ${ }^{35,36}$ Participant accrual was recently completed in the prospective observational Pregnancy Outcome and Safety of Interrupting Therapy for Women with Endocrine Responsive Breast Cancer (POSITIVE) trial (ClinicalTrials.gov identifier NCT02308085), which is aimed at determining the cancer and pregnancy outcomes of patients with breast cancer who interrupt adjuvant hormonal therapy after 18-30 months to attempt pregnancy.

\section{Controlled ovarian stimulation for fertility preservation}

Theoretically, the estrogen levels induced by ovarian stimulation may accelerate the growth of any micrometastases remaining after resection of ER+ tumours (before administration of adjuvant systemic therapy) or of the untreated macroscopic local/regional disease of women scheduled for neoadjuvant chemotherapy before surgery. Therefore, to reduce serum estrogen levels during ovarian stimulation, it is common to use aromatase inhibitors such as letrozole in conjunction with gonadotropin stimulation. ${ }^{38}$ Peak estrogen levels during the few days of stimulation are one-fifth to one-tenth the levels maintained over a period of several months during pregnancy. ${ }^{39}$ All studies to date have shown similar or better cancer outcomes for patients with breast cancer who underwent ovarian stimulation compared to matched patients who did not. ${ }^{39-42}$ However, all these studies had relatively short follow-up durations ( $<7 \mathrm{yr}$ ), and, in several, there were potentially important differences between case and control participants. ${ }^{43}$ In the only study that included a substantial number of women who underwent ovarian stimulation before surgical removal of the tumour, no increase in cancer recurrence was seen after a median follow-up duration of 43 months. ${ }^{39}$

As the widespread adoption of egg or embryo cryopreservation for fertility preservation is relatively recent, there are few reports of breast cancer outcomes for women who conceived after embryo transfer compared to those who conceived naturally. No study to date has shown an increase in the risk of cancer recurrence. $^{44}$

\section{Ovarian suppression with gonadotropin-releasing hormone agonists}

In a meta-analysis of 873 patients with breast cancer in 5 trials who were randomly allocated to receive or not receive a gonadotropin-releasing hormone agonist during chemotherapy for ovarian suppression, no significant reduction in disease-free survival or overall survival in the gonadotropin-releasing hormone agonist group was seen, regardless of receptor status. ${ }^{34}$

\section{Fertility-preservation resources}

Several excellent information resources and decision aids have been developed in the last few years for patients and health care providers to facilitate discussion and decision-making (Box 2). A pamphlet, option grid or website address should be routinely provided to patients by the oncology team at the time of fertility clinic referral. 
Box 2: Fertility-preservation resources for patients and health care providers

\section{Patients}

- American Society of Reproductive Medicine patient education video, www.reproductivefacts.org/resources/educational-videos /videos/full-length-videos/videos/fertility-preservation-for-cancer -patients/?_ga = 2.124770254.531824791.1588016469-586388077 .1547138741

- Oncofertility Consortium, http://oncofertility.northwestern.edu/ for-patients

- American Society of Clinical Oncology online information for patients, www.cancer.net/navigating-cancer-care/dating-sex -and-reproduction/fertility-concerns-and-preservation-women

- Fertile Future (Power of Hope Program), https://fertilefuture.ca/ programs/power-of-hope/

- Decision aid: https://fertilityaid.rethinkbreastcancer.com/ decision-aid/

- Option grid (1 page): www.womensresearch.ca/research-areas/ cancer/ruby-study/fertility-preservation

\section{Health care providers}

- American Society of Reproductive Medicine guideline document, www.asrm.org/globalassets/asrm/asrm-content/news-and -publications/practice-guidelines/for-non-members/fertility_ preservation_in_patients_undergoing_gonadotoxic_therapy_ or_gonadectomy.pdf

- Oncofertility Consortium, http://oncofertility.northwestern.edu/

- International Society for Fertility Preservation, www.isfp-fertility.org/

- Canadian Fertility and Andrology Society, https://cfas.ca/

- American Society of Clinical Oncology 2018 guideline update, https://ascopubs.org/doi/pdf/10.1200/JCO.2018.78.1914

\section{Conclusion}

Most patients with breast cancer diagnosed during their reproductive years will require gonadotoxic adjuvant systemic chemotherapy. Explanation of the detrimental effect of chemotherapy on ovarian function in general and on fertility in particular should be part of the chemotherapy informed-consent process. Routinely discussing childbearing plans with young patients with breast cancer as soon as possible after their diagnosis and offering prompt referral to a fertility clinic to those who have not yet completed their families enables these women to choose from a number of safe and increasingly successful fertility-preservation options without delaying their cancer treatment. Moreover, merely having such a discussion sends these young women the powerfully positive message that they are expected to not only have a normal lifespan but also to continue to pursue the goals and dreams they had before their illness.

\section{References}

1. Canadian Cancer Statistics Advisory Committee. Canadian cancer statistics 2019. Toronto: Canadian Cancer Society; 2019. Available: www.cancer.ca/ Canadian-Cancer-Statistics-2019-EN (accessed 2019 Nov. 29).

2. Ruddy KJ, Geller SI, Tamimi RM, et al. Prospective study of fertility concerns and preservation strategies in young women with breast cancer. J Clin Oncol 2014;32:1151-6.
3. Ruggeri M, Pagan E, Bagnardi V, et al. Fertility concerns, preservation strategies and quality of life in young women with breast cancer: baseline results from an ongoing prospective cohort study in selected European centers. Breast 2019;47:85-92.

4. Deshpande NA, Braun IM, Meyer FL. Impact of fertility preservation counseling and treatment on psychological outcomes among women with cancer: a systematic review. Cancer 2015;121:3938-47.

5. Peate $M$, Meiser B, Hickey $M$, et al. The fertility-related concerns, needs and preferences of younger women with breast cancer: a systematic review. Breast Cancer Res Treat 2009;116:215-23.

6. Gorman JR, Usita PM, Madlensky L, et al. Young breast cancer survivors: their perspectives on treatment and fertility concerns. Cancer Nurs 2011;34:32-40.

7. Partridge AH, Ruddy KJ, Barry WT, et al. A randomized study to improve care for young women with breast cancer at community and academic oncology practices in the United States: the Young and Strong study. Cancer 2019;125: 1799-806.

8. Lambertini M, Di Maio M, Pagani O, et al. A survey on physicians' knowledge, practice and attitudes on fertility and pregnancy issues in young breast cancer patients. Breast 2017;32(Suppl 1):S85-6.

9. Wallace WHB, Kelsey TW. Human ovarian reserve from conception to the menopause. PLoS One 2010;5:e8772.

10. Azim HA Jr, Partridge AH. Biology of breast cancer in young women. Breast Cancer Res 2014;16:427.

11. Donnez J, Dolmans MM. Fertility preservation in women. N Engl J Med 2017; 377:1657-65.

12. Letourneau JM, Ebbel EE, Katz PP, et al. Acute ovarian failure underestimates age-specific reproductive impairment for young women undergoing chemotherapy for cancer. Cancer 2012;118:1933-9.

13. Poorvu PD, Frazier AL, Feraco AM, et al. Cancer treatment related infertility: a critical review of the evidence. JNCI Cancer Spectr 2019;3:pkz008.

14. Ter Welle-Butalid MEE, Vriens IJHI, Derhaag JGJ, et al. Counseling young women with early breast cancer on fertility preservation. J Assist Reprod Genet 2019;36:2593-604.

15. Anderson RA, Remedios R, Kirkwood AA, et al. Determinants of ovarian function after response-adapted therapy in patients with advanced Hodgkin's lymphoma (RATHL): a secondary analysis of a randomised phase 3 trial. Lancet Oncol 2018;19:1328-37.

16. Wo JY, Viswanathan AN. The impact of radiotherapy on fertility, pregnancy and neonatal outcomes of female cancer patients. Int J Radiat Oncol Biol Phys 2009; 73:1304-12.

17. Levine JM, Kelvin JF, Quinn GP, et al. Infertility in reproductive-age female cancer survivors. Cancer 2015;121:1532-9.

18. Duffy CM, Allen SM, Clark MA. Discussions regarding reproductive health for young women with breast cancer undergoing chemotherapy. J Clin Oncol 2005;23:766-73.

19. Copson ER, Maishman TC, Tapper WJ, et al. Germline BRCA mutations and outcome in young-onset breast cancer (POSH): a prospective cohort study. Lancet Oncol 2018;19:169-80.

20. Lee SJ, Schover LR, Partridge AH, et al.; American Society of Clinical Oncology. American Society of Clinical Oncology recommendations on fertility preservation in cancer patients. J Clin Oncol 2006;24:2917-31.

21. Loren AW, Mangu PB, Beck LN, et al.; American Society of Clinical Oncology. Fertility preservation for patients with cancer: American Society of Clinical Oncology clinical practice guideline update. J Clin Oncol 2013;31:2500-10.

22. Oktay K, Harvey BE, Partridge AH, et al. Fertility preservation in patients with cancer: ASCO clinical practice guideline update. J Clin Oncol 2018;36: 1994-2001.

23. Canadian Assisted Reproductive Technologies Register Plus (CARTR Plus) Canadian Fertility and Andrology Society. 65th Annual Meeting; 2019 Sept. 19-21; Ottawa. Available: https://cfas.ca/_Library/CARTR/CFAS_CARTR_Plus_ presentation_plenary_slides_FINAL_for_website_-_opened.pdf (accessed 2020 May 10).

24. Massarotti C, Scaruffi P, Lambertini M, et al. State of the art on oocyte cryopreservation in female cancer patients: a critical review of the literature. Cancer Treat Rev 2017;57:50-7.

25. Levine JM, Kelvin JF, Quinn GP, et al. Infertility in reproductive-age female cancer survivors. Cancer 2015;121:1532-9.

26. Cobo A, García-Velasco JA, Coello A, et al. Oocyte vitrification as an efficient option for elective fertility preservation. Fertil Steril 2016;105:755-64.e8.

27. Cobo A, García-Velasco J, Domingo J, et al. Elective and onco-fertility preservation: factors related to IVF outcomes. Hum Reprod 2018;33:2222-31. 
28. Vuković P, Kasum M, Raguž J, et al. Fertility preservation in young women with early stage breast cancer. Acta Clin Croat 2019;58:147-56.

29. Peccatori FA, Mangili G, Bergamini A, et al. Fertility preservation in women harboring deleterious BRCA mutations: Ready for prime time? Hum Reprod 2018;33:181-7.

30. Pacheco F, Oktay K. Current success and efficiency of autologous ovarian transplantation: a meta-analysis. Reprod Sci 2017;24:1111-20.

31. Practice Committee of the American Society for Reproductive Medicine. Fertility preservation in patients undergoing gonadotoxic therapy or gonadectomy: a committee opinion. Fertil Steril 2019;112:1022-33.

32. Lambertini M, Richard F, Nguyen B, et al. Ovarian function and fertility preservation in breast cancer: Should gonadotropin-releasing hormone agonist be administered to all premenopausal patients receiving chemotherapy? Clin Med Insights Reprod Health 2019;13:1179558119828393.

33. Lambertini M, Ceppi M, Poggio $F$, et al. Ovarian suppression using luteinizing hormone-releasing hormone agonists during chemotherapy to preserve ovarian function and fertility of breast cancer patients; a meta-analysis of randomized studies. Ann Oncol 2015;26:2408-19.

34. Lambertini M, Moore HCF, Leonard RCF, et al. Gonadotrophin-releasing hormone antagonists during chemotherapy for preservation of ovarian function and fertility in premenopausal patients with early breast cancer: a systematic review and meta-analysis of individual patient-level data. J Clin Oncol 2018;36: 1981-90.

35. Lambertini M, Kroman N, Ameye L, et al. Long-term safety of pregnancy following breast cancer according to estrogen receptor status. J Natl Cancer Inst 2018;110:426-9.
36. Chuang SC, Lin CH, Lu YS, et al. Mortality of pregnancy following breast cancer diagnoses in Taiwanese women. Oncologist 2019;25:e252-8.

37. Berger JC, Clericuzio CL. Pierre Robin sequence associated with first trimester fetal tamoxifen exposure. Am J Med Genet A 2008;146A:2141-4.

38. Oktay K, Buyuk E, Libertella N, et al. Fertility preservation in breast cancer patients: a prospective controlled comparison of ovarian stimulation with tamoxifen and letrozole for embryo cryopreservation. J Clin Oncol 2005;23:4347-53.

39. Letourneau JM, Wald K, Sinha N, et al. Fertility preservation before breast cancer treatment appears unlikely to affect disease-free survival at a median follow-up of 43 months after fertility-preservation consultation. Cancer 2020;126:487-95.

40. Rodriguez-Wallberg KA, Eloranta S, Krawiec K, et al. Safety of fertility preservation in breast cancer patients in a register-based matched cohort study. Breast Cancer Res Treat 2018;167:761-9.

41. Rodgers RJ, Reid GD, Koch J, et al. The safety and efficacy of controlled ovarian hyperstimulation for fertility preservation in women with early breast cancer: a systematic review. Hum Reprod 2017;32:1033-45.

42. Muñoz E, Domingo J, De Castro G, et al. Ovarian stimulation for oocyte vitrification does not modify disease-free survival and overall survival rates in patients with early breast cancer. Reprod Biomed Online 2019;39:860-7.

43. Lambertini M, Fontanella C. How reliable are the safety data on hormona stimulation for fertility preservation in young women with newly diagnosed early breast cancer? Breast Cancer Res Treat 2018;168:773-4.

44. Goldrat O, Kroman N, Peccatori FA, et al. Pregnancy following breast cancer using assisted reproduction and its effect on long-term outcome. Eur J Cancer 2015;51:1490-6.
Competing interests: Karen Glass received an honorarium for an educational speaker event from Merck \& Co. in 2019. Shu Foong is the medical director of the Regional Fertility Program in Calgary, Alta. No other competing interests were declared.

This article has been peer reviewed.

Affiliations: Divisions of Medical Oncology (Warner) and Obstetrics/Gynecology (Glass), Sunnybrook Odette Cancer Centre; CReATe
Fertility Centre (Glass); University of Toronto (Warner, Glass), Toronto, Ont.; Regional Fertility Program (Foong); University of Calgary (Foong, Sandwith), Calgary, Alta.

Contributors: Ellen Warner and Emily Sandwith drafted the manuscript, and Karen Glass and Shu Foong revised it critically for important intellectual content. All of the authors interpreted the data, approved the final version to be published and agreed to be accountable for all aspects of the work.
Funding: This work was supported by a grant from the Canadian Institutes of Health Research and the Canadian Breast Cancer Foundation (OBW139590).

Acknowledgements: The authors thank Samantha Yee and Maureen Seminsky for their helpful suggestions regarding the content and wording of a previous version of the manuscript.

Correspondence to: Ellen Warner, ellen.warner@sunnybrook.ca 